\title{
Sulfatide interacts with and activates integrin aV $\beta 3$ in human hepatocellular carcinoma cells
}

\author{
Rong Wang ${ }^{1,2, *}$, Bing $\mathbf{Q i}^{1,2, *}$, Yi Wei Dong ${ }^{1,2}$, Qian Qian Cai ${ }^{1,2}$, Nian Hui Deng ${ }^{3}$, Qi Chen ${ }^{3}$, \\ Chao $\mathbf{L i}^{1}$, Yu Tong Jin ${ }^{1}$, Xing Zhong Wu $\mathbf{u}^{1,2}$ \\ ${ }^{1}$ Department of Biochemistry and Molecular Biology, School of Basic Medical Sciences, Fudan University, Shanghai, \\ P.R. China \\ ${ }^{2}$ Key Laboratory of Glycoconjugate Research, Ministry of Public Health, Shanghai, P.R. China \\ ${ }^{3}$ Yu Ying Children's Hospital, Wenzhou Medical University, Wenzhou, P.R. China \\ *These authors have contributed equally to this study \\ Correspondence to: Xing Zhong Wu, e-mail: xz_wu@shmu.edu.cn
}

Keywords: integrin, sulfated cerebroside, clustering, signaling, hepatocellular carcinoma

Received: October 09, $2015 \quad$ Accepted: April 16, $2016 \quad$ Published: April 29, 2016

\section{ABSTRACT}

Integrin aV $\beta 3$ is a malignant driver of anchorage-independence and tumor angiogenesis, but its dysregulation in hepatocellular carcinoma (HCC) remains unclear. In this study, we observed that sulfatide significantly promoted integrin aV(ITGAV) expression and wound closure in HCC. We also noted that elevated sulfatide profoundly stimulated integrin aV $\beta 3$ clustering and signaling. In the cells with integrin aV $\beta 3$ clustering induced by sulfatide, integrin $\beta 3$ subunit was phosphorylated. Simultaneously, focal adhesion kinase (FAK), Src and paxillin were also phosphorylated. Treatment with FAK inhibitor resulted in robust suppression of FAK-Y397 and Src-Y416 phosphorylation stimulated by sulfatide, but not suppression of integrin $\beta 3$ phosphorylation. Src inhibitors repressed Src-Y416 and FAK Y861 and Y925 phosphorylation, but not FAK-Y397 and integrin $\beta 3$ phosphorylation. After mutation of integrin $\beta 3$ (Y773F and Y785F), FAK or Src phosphorylation failed to be stimulated by sulfatide. Moreover, $\beta 3$ Y773 and Y785 phosphorylation was suppressed by insulin-like growth factor receptor knockdown even in cells stimulated by sulfatide. In assays of immunoprecipitation and immunostaining with integrin $a V$ or $\beta 3$ antibody, labeled sulfatide was found in the complex and co-localized with integrin aV $\beta 3$. Taken together, this study demonstrated that elevated sulfatide bound to integrin $\alpha \mathrm{V} \beta 3$ and induced clustering and phosphorylation of aV $\beta 3$ instead of matrix ligand binding, triggering outside-in signaling.

\section{INTRODUCTION}

Hepatocellular carcinoma (HCC) is one of the most malignant diseases worldwide, especially in Asia, where there is a high prevalence of chronic viral hepatitis infection. Tumor metastasis is the major cause of HCCrelated mortality. Invasive primary HCC breaches the basement membrane and invades the lymphatic or blood microvessels, from where the tumor cells are transported to distant sites to form dormant micrometastases which may eventually acquire the ability of colonization and angiogenesis, enabling them to form a macroscopic metastasis [1]. HCC commonly metastasizes to the lungs, lymph nodes, adrenal gland and bone. Metastasis process is closely associated with cell migration and adhesion that are mostly integrin dependent, which resides on the cell surface and interacts with extracellular matrix (ECM) proteins. Although some integrins inhibit tumor cell proliferation via inducing apoptosis or cell death [2], Integrin $\alpha \mathrm{V} \beta 3$ is required for tumor angiogenesis [3] and anchorage-independent proliferation of cancer cells $[4,5]$. Expression of integrin $\alpha \mathrm{V} \beta 3$ is upregulated in the vasculature associated with solid tumors [3, 4], indicating that integrin $\alpha \mathrm{V} \beta 3$ is involved in angiogenesis [6] and tumor metastasis $[5,7,8]$. Integrin $\alpha \mathrm{V} \beta 3$ is especially expressed on the most aggressive protruding tumor 
cells that invade normal tissue, in many cancers such as melanoma and carcinomas of pancreas [5]. The expression of integrin $\alpha \mathrm{V} \beta 3$ is often correlated with prostate cancer metastasis [9] and poor prognosis of patients with cervical carcinoma $[10,11]$. Integrin $\alpha \mathrm{V} \beta 3$ expression contributes breast cancer cell migration and metastasis since exogenous expression of integrin $\alpha \mathrm{V} \beta 3$ in human breast cancer cells rescues the invasiveness and migration that are suppressed by MYC [7]. The antagonists of integrin $\alpha \mathrm{V} \beta 3$ obviously inhibited the tumor aggressiveness by inducing apoptosis of proliferative angiogenic vascular cells [4].

The noncatalytic cytoplasmic tail (CT) domain of integrin $\beta 3$ subunit is laden with various phosphorylation sites, including two tyrosine residues, one serine, and multiple threonine residues [12]. The two tyrosine phosphorylation sites, which are located within NPXY(asparagine-proline-X-tyrosine) and/or NPXY-like motifs, can be recognized by talin or kindlin, an important integrin activator, and interact with phosphotyrosine binding domains of intracellular signaling mediators such as Dok1(docking protein 1) or Shc (Src homology and collagen homology) after phosphorylation, to regulate integrin activation and signaling [13]. In mice, the two tyrosine phosphorylation sites in the $\beta 3$ subunit CT are Tyr747(Y747) and Tyr(Y759), which are involved in the signal transduction associated with tyrosine phosphorylation of focal adhesion kinase (FAK) and paxillin [14]. The corresponding tyrosine sites in humans are Y773 and Y785 [15]. Integrin tyrosine phosphorylation takes place upon ligand binding to the $\alpha \operatorname{IIb} \beta 3$ integrin. The cytoplasmic domain of integrin $\beta 3$ subunit may serve as a substrate for $\mathrm{v}$-Src kinase to regulate integrin activation and cell adhesion [16]. Blocking of $\alpha \mathrm{V} \beta 3$ binding to its ligands by adding exogenous polyamines to the fibronectin matrix can also prevent Src activation [17]. However overexpressed integrin $\alpha \mathrm{V} \beta 3$ recruits and activates c-Src by integrin $\beta 3 \mathrm{CT}$ in independence on ligand binding, and forms an oncogenic unit to stimulate anchorageindependent proliferation of tumor cells [5]. Thus integrin $\alpha \mathrm{V} \beta 3$, the primary vitronectin receptor, plays an important role in the events of metastasis and angiogenesis. Any change of integrin $\alpha \mathrm{V} \beta 3$ activity will affect tumor proliferation and metastasis. However the dysregulation of integrin $\alpha \mathrm{V} \beta 3$ in tumor cells remains largely unknown and how overexpressed integrin $\alpha \mathrm{V} \beta 3$ activates c-Src without ligand binding is also not clear.

Sulfatide is a cell membrane component that is modified from cerebroside by adding a sulfate group by cerebroside sulfotransferase(CST). Sulfatide is significantly elevated in some cancers such as HCC. Nevertheless, the biological and pathological significance of elevated sulfatide in HCC is largely unknown [18]. Our previous studies showed that sulfatide promotes cell adhesion to vitronectin and metastasis of tumor cells in HCC [19] via modulation of integrin $\alpha \mathrm{V}$ subunit expression by phosphorylated transcriptional factor Sp1 (specificity protein 1) [20] and miR-223 [21]. However, the detailed process of how sulfatide stimulates integrinmediated cell adhesion and migration, and how it triggers the phosphorylation cascades remain elusive. We hypothesize that sulfatide interacts with and activates the integrin $\alpha \mathrm{V} \beta 3$ heterodimer, and triggers signaling by phosphorylation cascades. To test this, we investigated the effects of elevated sulfatide on the clustering and phosphorylation of integrin $\alpha \mathrm{V} \beta 3$ and its signaling in HCC.

\section{RESULTS}

\section{Sulfatide stimulation of HCC integrin $\alpha \mathrm{V}$ expression}

As compared to DMSO control, galactocerebroside, lactocerebroside and ganglioside, sulfatide interestingly enhanced the expression of integrin $\alpha \mathrm{V}$ subunit (Figure 1A) in both human hepatocellular carcinoma cells (SMMC-7721 and BEL-7404), but not integrin $\beta 1,3$ or 5 . To investigate further the regulation by sulfatide, the expression profile of integrins was measured. The results of quantitative PCR showed that the level of integrin $\alpha \mathrm{V}$ subunit expression was significantly elevated by sulfatide treatment in either SMMC-7721 or BEL-7404 cells (Figure 1B). The enhanced expression of integrin $\alpha \mathrm{V}$ subunit by sulfatide was confirmed by western blotting and qPCR measurement (Figure 1C). We observed that exposure to sulfatide resulted in significantly faster wound closure in both SMMC-7721 and BEL-7404 cells than in the control cells (Figure 1D) by wound healing assay. SMMC-7721 cell migration through the microporous membrane was also significantly faster in the presence of sulfatide than in the control (Figure 1D right). Phallodin immunostaining of the cells treated with sulfatide indicated an increase in the amount of actin fiber polymerization in the vicinity of the leading plasma membrane compared to Gal-Cer (Figure $1 \mathrm{E})$. The actin filaments were well organized in sulfatidetreated cells with more lamellipodia.

\section{Integrin $\alpha \mathrm{V}$ clustering}

To uncover the initial regulation event in the HCC cells, we investigated and observed integrin clustering activity after treatment. Compared to control groups, cells treated with sulfatide showed extensive clustering of integrin $\alpha \mathrm{V}$, which was similar to the clustering induced by specific antibody against integrin $\alpha \mathrm{V}$ (Figure 2A). In order to confirm the roles of integrin $\alpha \mathrm{V} \beta 3$ in sulfatide-mediated wound healing or cell migration in $\mathrm{HCC}$, integrin $\alpha \mathrm{V}$ and $\beta 3$ expression was knocked down by RNA interference and confirmed by western blotting (Figure 2B) in SMMC7721 cells in which other types of integrin were not targeted (data not shown). Knockdown of integrin $\alpha \mathrm{V}$ or 
A
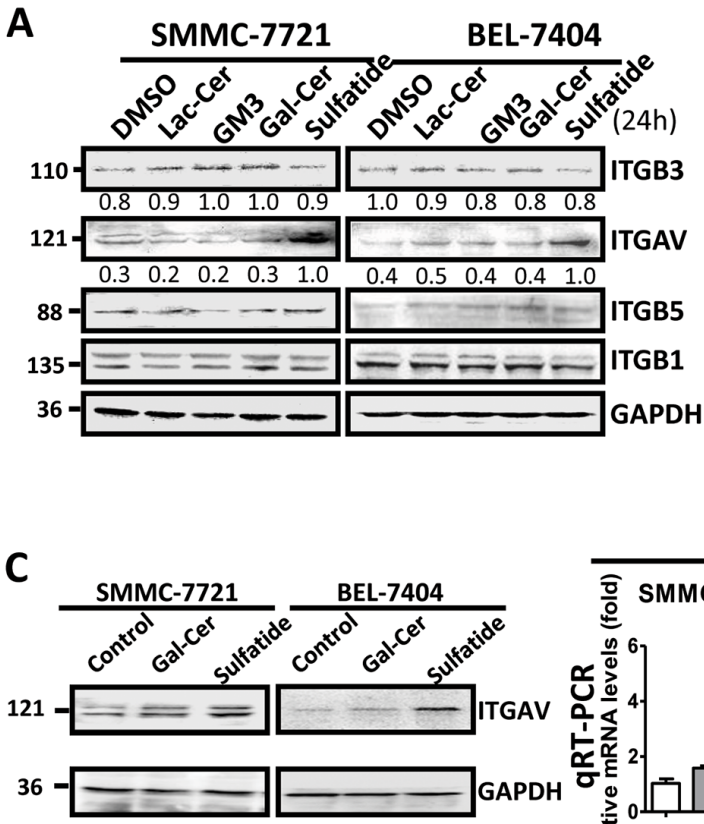

D
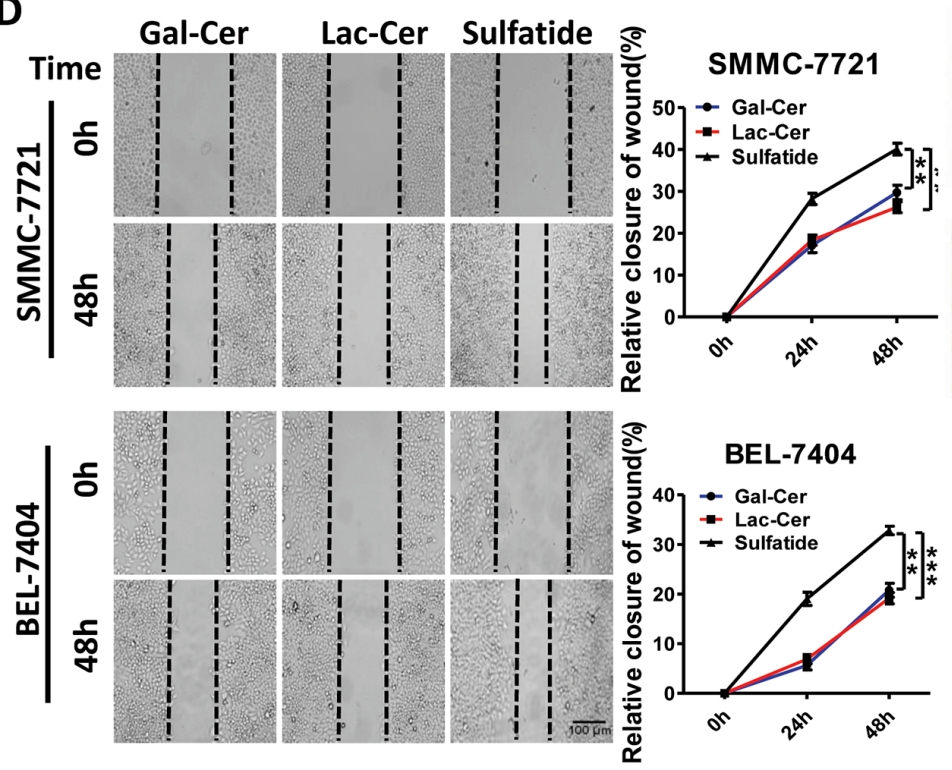

B
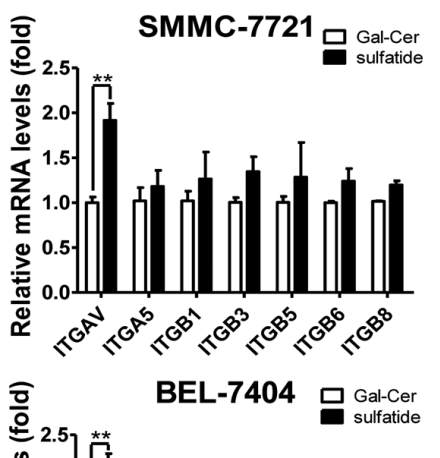

ITGAV
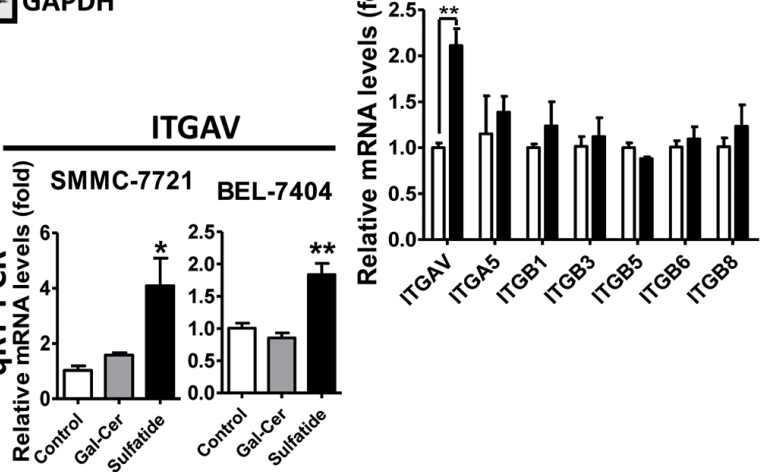
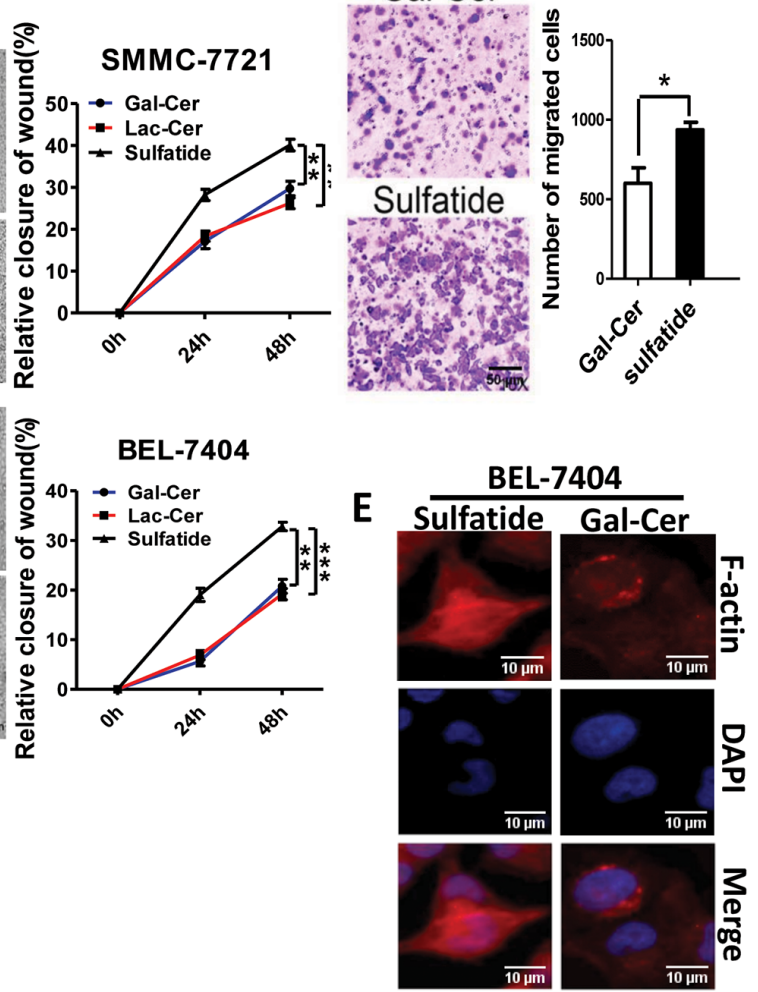

Figure 1: Sulfatide enhanced integrin $\alpha \mathrm{V}$ expression and wound healing in HCC. A. Protein levels of integrin $\alpha \mathrm{V}, \beta 1, \beta 3$ and $\beta 5$ were measured by western blotting in SMMC-7721 and BEL-7404 cells treated with $2 \mu \mathrm{M}$ Gal-Cer, sulfatide or an equivalent volume of DMSO $(0.1 \% \mathrm{v} / \mathrm{v})$ for $24 \mathrm{~h}$. B. Expression of integrin subunits $\alpha \mathrm{V}, \alpha 5, \beta 1, \beta 3, \beta 5, \beta 6$ and $\beta 8$ was examined by quantitative RT-PCR in $\mathrm{HCC}$ cells upon sulfatide treatment. C. Expression levels of integrin $\alpha \mathrm{V}$ were examined by RT-PCR and western blotting. D. Representative micrograph of wound healing assays (left) in SMMC-7721 and BEL-7404 cells. The ratio of wound closure was measured after scratching and the quantitative analysis of relative closure is on the middle. Original magnification: 100×. Representative micrograph of cell migration assays in SMMC-7721 cells treated with Gal-Cer or sulfatide $24 \mathrm{~h}$ before the assay (right upper) and quantitative analysis. Original magnification: 100×. E. Representative images of actin filaments stained with rhodamine-conjugated phalloidin (red), and nuclei with DAPI (blue) in BEL-7404 cells treated with $2 \mu \mathrm{M}$ sulfatide for $12 \mathrm{~h}$. Original magnification: 400×. Bars indicate scales. Data are representative of three independent experiments. Gal-Cer: galactocerebroside, Lac-Cer: lactocerebroside, ${ }^{* *} P<0.01,{ }^{* * *} P<0.001$. 

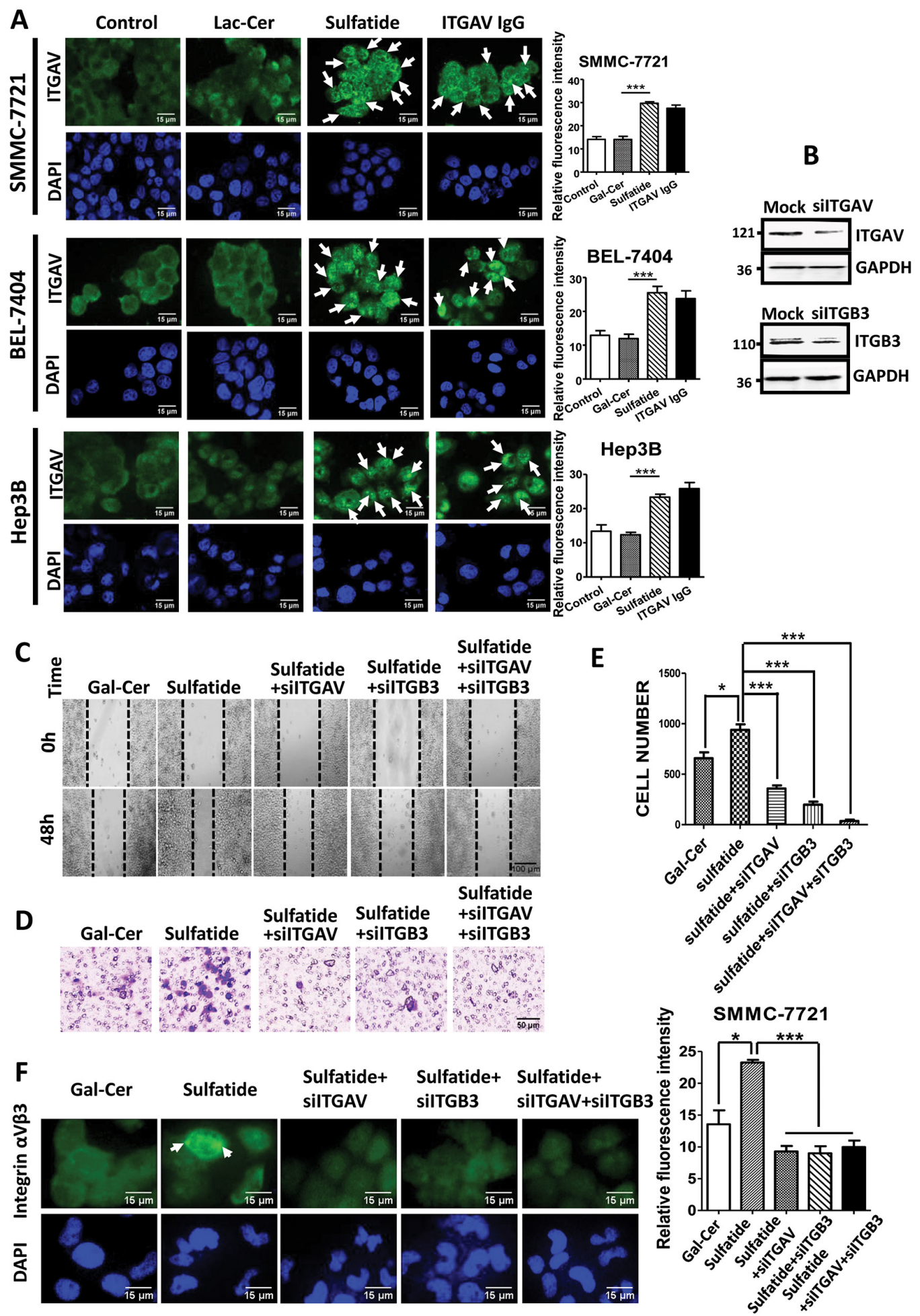

Figure 2: Sulfatide-induced clustering of integrin $\boldsymbol{\alpha V \beta 3}$. A. Representative images of integrin $\alpha \mathrm{V}$ clustering in SMMC-7721, BEL-7404 and Hep3B cells treated with $2 \mu \mathrm{M}$ sulfatide or $10 \mu \mathrm{g} / \mathrm{mL}$ integrin $\alpha \mathrm{V} \mathrm{IgG}$ antibody. Arrowheads indicate integrin clustering. Quantitative analysis of the clustering fluorescence signals is on the right. Original magnification: $400 \times$. B. Knockdown of integrin $\alpha \mathrm{V}$ or $\beta 3$ expression (siITGAV and siITGB3) by RNA interference was validated via western blot analysis. C. Representative micrograph of wound healing in SMMC-7721 cells with integrin $\alpha \mathrm{V}$ and $\beta 3$ knockdown. D. Representative migration images of SMMC-7721 cells treated with sulfatide. E. Quantitative analysis of the migrated cells in D, F. Representative micrographs of integrin $\alpha \mathrm{V} \beta 3$ clustering in SMMC-7721 cells transfected with siITGAV, siITGB3, or co-transfected with siITGAV + siITGB3. Green: integrin $\alpha$ V $\beta 3$; Blue: nucleus. Original magnification: $400 \times$. Data are representative of at least three independent experiments. $* P<0.05, * * P<0.01, * * * P<0.001$. n.s. not significant. 
$\beta 3$ subunit significantly suppressed sulfatide-stimulated wound closure (Figure 2C). Cell migration through the microporous membrane also significantly slowed down in the silenced cells (Figure 2D, 2E). Importantly, integrin $\alpha \mathrm{V} \beta 3$ clustering stimulated by sulfatide was completely suppressed by knockdown of integrin $\alpha \mathrm{V}$ or $\beta 3$ (Figure 2F).

\section{Activation of integrin $\alpha \mathrm{V} \beta 3$ signaling}

Lateral association and clustering of integrins require integrin activation which is accompanied by tyrosine phosphorylation of the $\beta 3$ subunit. Although the level of phosphorylated integrin $\beta 3$ at Y773 and Y785 seemed not significantly different $24 \mathrm{~h}$ after sulfatide treatment (Figure 3A), a significant increase in the level of phospho-integrin $\beta 3-Y 773$ and phospho- $\beta 3-Y 785$ was observed within $2 \mathrm{~h}$ after treatment (Figure 3B). Simultaneously, shortly after SMMC-7721 and BEL7404 cells were treated with sulfatide, the levels of the phosphorylated FAK-Y397, FAK-Y861, FAK-Y925, Src-Y416 were significantly strengthened (Figure 3C).The phosphorylated levels of paxillin-Y31 and caveolin-Y14 were also interestingly enhanced (Figure 3D). This suggested that sulfatide stimulated integrin $\alpha \mathrm{V} \beta 3$ and activated FAK-Src signaling.

\section{Sequential activation of FAK and Src}

Now in the cells treated with sulfatide, integrin $\alpha \mathrm{V} \beta 3$ was activated. FAK and Src were also observed that they were phosphorylated and activated. To study further their role in the integrin activation and signaling, we examined both FAK and Src inhibitors, and observed that they were phosphorylated and activated sequentially. FAK inhibitor 14 significantly suppressed the sulfatidestimulated phosphorylation of FAK on Y397 and attenuated the activation of Src (p-Src-Y416), but not phosphorylated integrin $\beta 3$ ( $\beta 3$-Y773) (Figure 4A). However, Src inhibitors, PP2 and SU6656, decreased significantly sulfatide-stimulated FAK phosphorylation of p-FAK-861 and p-FAK-Y925, but not p-FAK-Y397 and p-integrin $\beta 3-Y 773$ (Figure 4B). These suggested that Src-Y416 phosphorylation was after FAK-Y397, but before FAK-861 and FAK-Y925 phosphorylation. We then mutated integrin $\beta 3$ Tyr773 and Tyr785 to phenylalanine, and found that the mutation of integrin $\beta 3$ markedly decreased FAK Y397 and Src Y416 phosphorylation in the sulfatide-stimulated cells (Figure 4C). However, sulfatidestimulated integrin $\alpha \mathrm{V} \beta 3$ clustering was attenuated by FAK inhibitor 14 and Src inhibitors (PP2 and SU6656) (Figure 4D). Also, sulfatide-stimulated wound healing was significantly inhibited by Src inhibitors (data not shown). Thus, sulfatide stimulated integrin $\alpha \mathrm{V} \beta 3$ clustering and phosphorylation, which triggered FAK-Src signaling, leading to HCC cell migration.

\section{Sulfatide binds to integrin $\alpha \mathrm{V} \beta 3$}

The integrin clustering correlates with integrin activation, which needs ligand binding in the process since the activated integrins require ligands to form integrin clusters and to induce tyrosine phosphorylation of the $\beta$ subunit. OPN is a small integrin-binding protein and can bind to integrin $\alpha \mathrm{V}$ via its RGD motif [22]. To understand the regulation of integrin by sulfatide, we examined the effect of OPN in HCC cells on integrin clustering. The results showed that overexpression of OPN indeed induced clustering of integrin $\alpha \mathrm{V} \beta 3$ and phosphorylation of FAK and Src (Figure 5A, 5B). Meanwhile, OPN also enhanced the wound closure capacity of SMMC-7721 cells (Figure $5 \mathrm{C}$ ). The effect of OPN that bound integrin $\alpha \mathrm{V} \beta 3$ on HCC seemed similar to sulfatide-stimulated HCC cell migration. To examine if sulfatide interacted with integrin $\alpha \mathrm{V} \beta 3$, SMMC-7721 cells were incubated with $10 \mu \mathrm{M}$ fluorescent BODIPY-tagged sulfatide or BODIPY-tagged Gal-Cer. The lysate was immunoprecipitated with integrin $\alpha \mathrm{V}$ or $\beta 3$ antibody. Fluorescence intensity was measured in the pellets precipitated by specific integrin $\alpha \mathrm{V}$ or $\beta 3$ antibody and the fluorescence signal was significantly higher in the Bodipy-sulfatide group than in the Bodipy or Bodipy-GalCer control (Figure 5D). Sulfatide was also co-localized with integrin $\alpha \mathrm{V}$ in fluorescence immunostaining (Figure $5 \mathrm{E})$. These results suggested that sulfatide interacted with integrin $\alpha \mathrm{V} \beta 3$.

\section{RGD peptide prevents sulfatide-stimulated signaling and cell migration}

Integrin $\alpha \mathrm{V} \beta 3$ binding to ligand molecules is through RGD-binding sites, and upon ligand binding, the cytoplasmic domain of the integrin $\beta$ subunit associates with signaling and cytoskeletal proteins. To investigate the role of RGD-binding site in $\alpha \mathrm{V} \beta 3$ and sulfatide interaction, we used the linear synthetic RGD peptide (GRGDSP) to block the RGD binding site of integrin $\alpha \mathrm{V} \beta 3$ with the negative control GRGESP. RGD peptide inhibited sulfatide-stimulated phosphorylation of integrin $\beta 3$-Y773, $\beta 3$-Y785, FAK-Y397, FAK-Y861, FAK-Y925 and Src-Y416 in both SMMC-7721 and BEL-7404 cells (Figure 6A). To determine further the impact of RGD peptide on sulfatide-induced integrin clustering and cell migration, we performed immunofluorescence and migration assays. RGD peptide significantly suppressed the clustering of integrin $\alpha \mathrm{V} \beta 3$ stimulated by sulfatide, whereas RGE peptide did not (Figure 6B). RGD peptide significantly retarded the wound closure capacity of SMMC-7721 cells even in the presence of sulfatide (Figure 6C). The migration was also slowed down (Figure 6D). This suggested that RGD-binding site was important in sulfatide interaction with integrin $\alpha \mathrm{V} \beta 3$, sulfatideinduced FAK-Src signaling, and cell behaviors. 
A
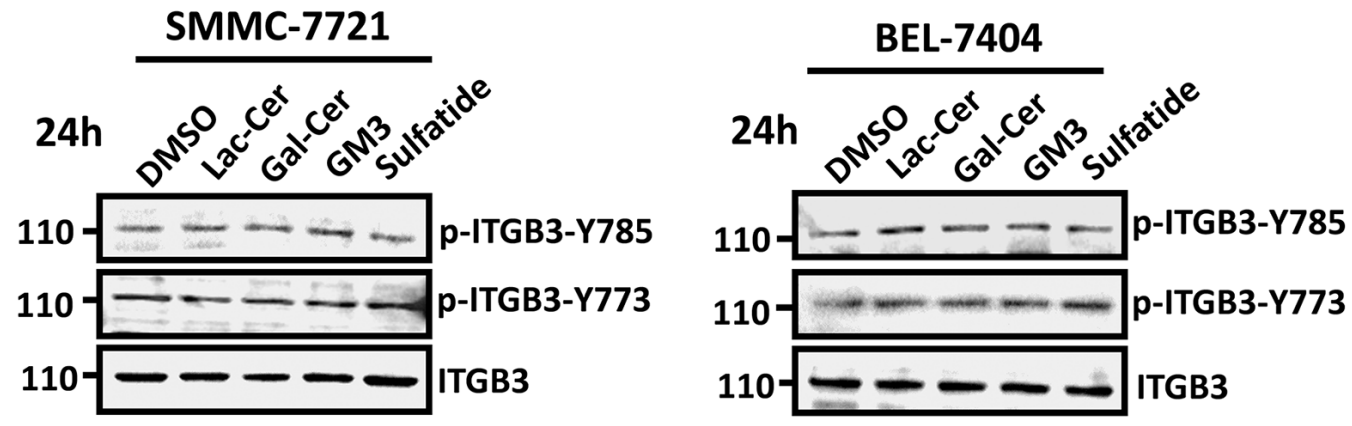

B
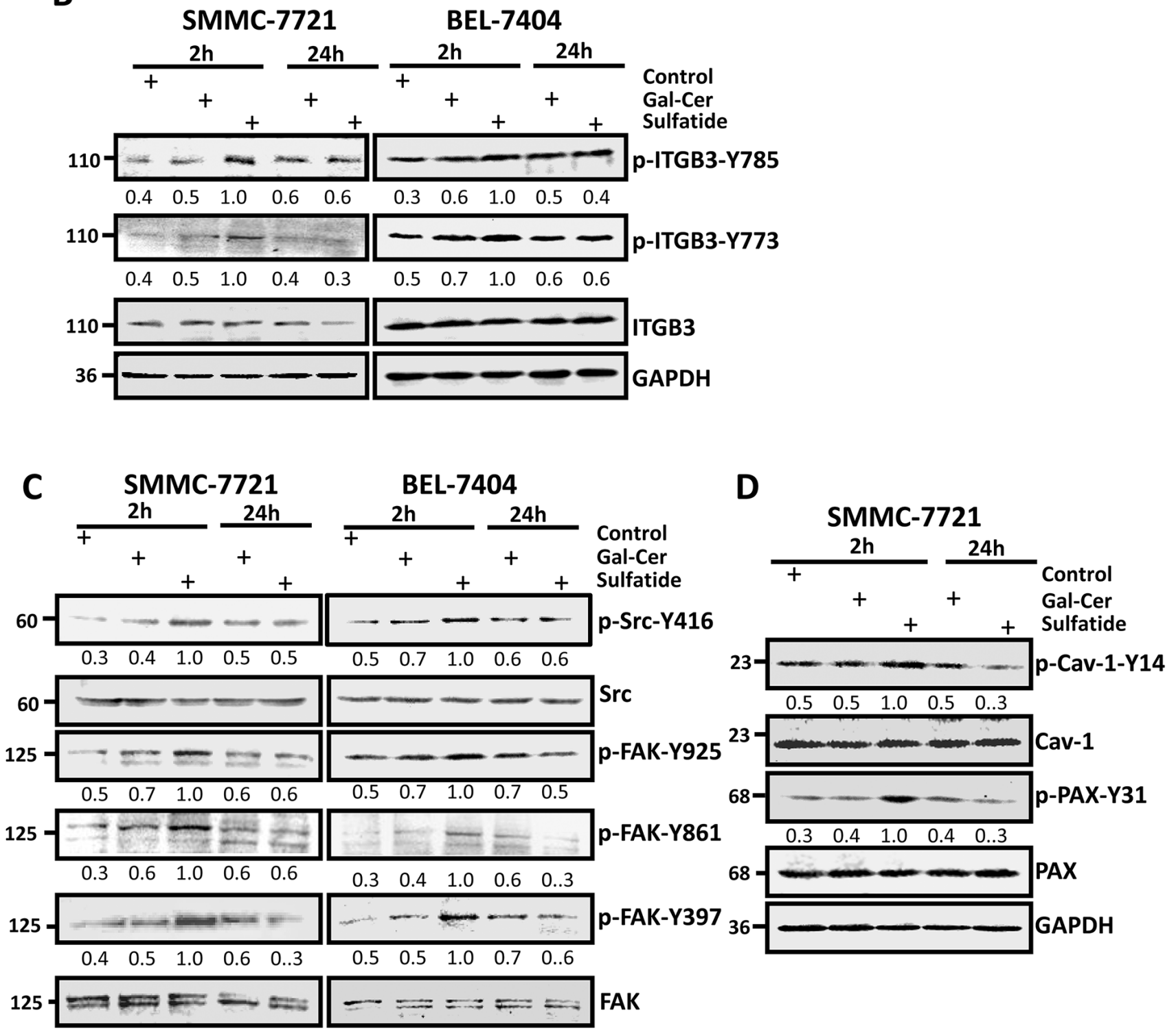

Figure 3: Sulfatide activated signaling in HCC cells. A. and B. Phosphorylation levels of integrin $\beta 3-Y 773$ and $\beta 3-Y 785$ were measured by Western blotting $24 \mathrm{~h}$ or $2 \mathrm{~h}$ after treatment with $2 \mu \mathrm{M}$ Lac-Cer, Gal-Cer, GM3, or sulfatide in SMMC-7721 and BEL-7404 cells. The bands were analyzed by densitometry and the relative value is shown under each band. C. Phosphorylation levels of FAK and Src were measured 2 or $24 \mathrm{~h}$ after sulfatide treatment by western blotting. The relative density value is shown under each band. D. Phosphorylation levels of paxillin and caveolin were measured 2 or $24 \mathrm{~h}$ after sulfatide treatment by western blotting. The relative value is shown under each band. Data are representative of three independent experiments. 

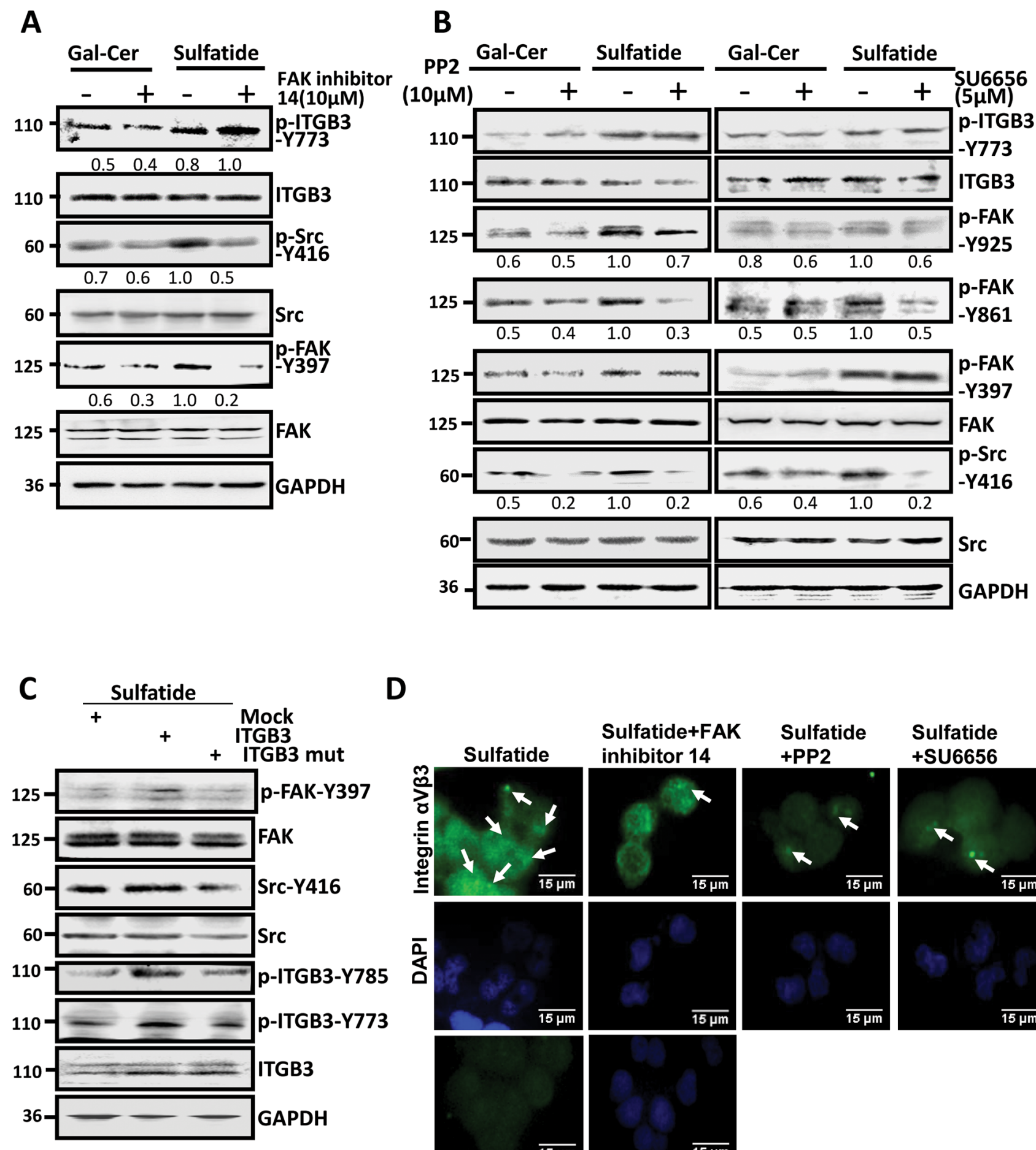

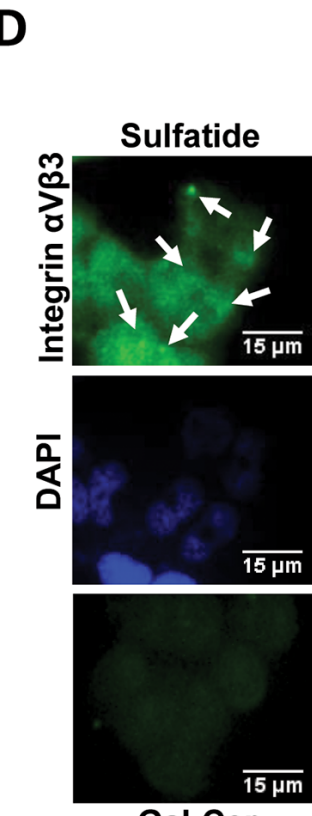

Gal-Cer
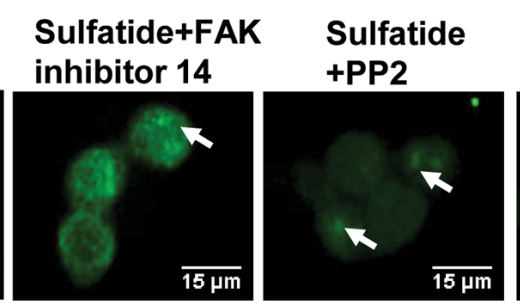

Sulfatide

+SU6656
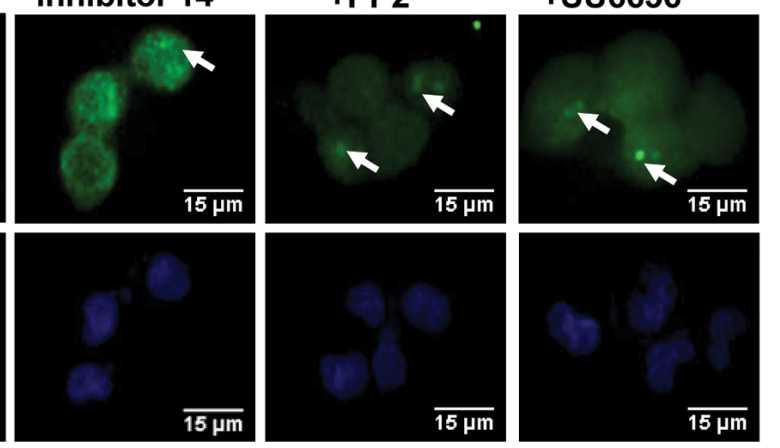

Figure 4: Sulfatide stimulated integrin $\alpha \mathrm{V} \beta 3$ and activated FAK-Src signaling. A. Phosphorylation of Src, FAK-Y397 and integrin $\beta 3$ subunit was measured in SMMC-7721 cells pretreated with FAK inhibitor $144 \mathrm{~h}$ prior to sulfatide. B. Phosphorylation levels of FAK-Y397, 861, 925 and integrin $\beta 3$-Y773 were determined by western blotting in SMMC-7721 cells pretreated with PP2 or SU6656 $4 \mathrm{~h}$ prior to sulfatide. C. Phosphorylation of FAK-Y397 and Src-Y416 induced by sulfatide was measured by western blotting in the cells transfected with mutated integrin $\beta 3$ (Y773F or Y785F) construct. D. Representative micrographs are integrin $\alpha \mathrm{V} \beta 3$ clustering induced by sulfatide after FAK and Src inhibition in SMMC-7721 cells. Green: integrin $\alpha \mathrm{V} \beta 3$; Blue: nucleus. Original magnification: 400×. Data are representative of three independent experiments. 

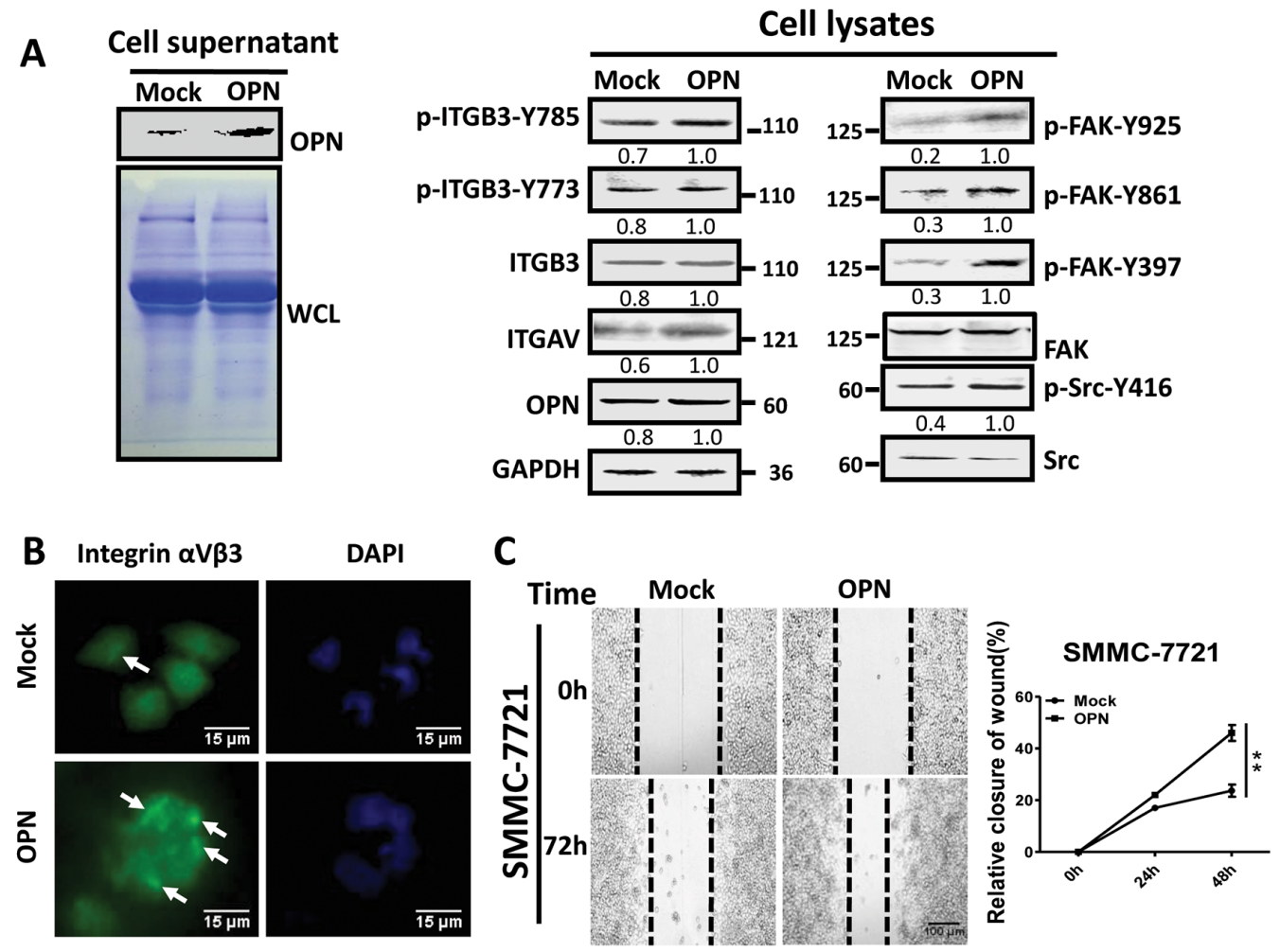

Relative fluorescence intensity
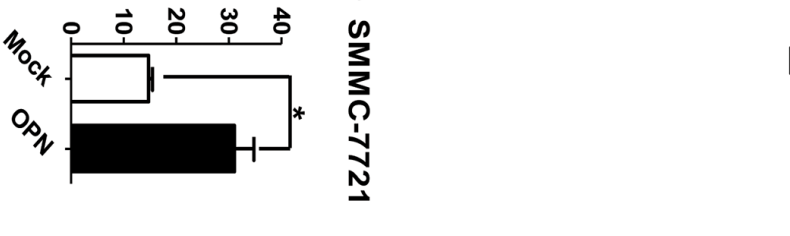

D
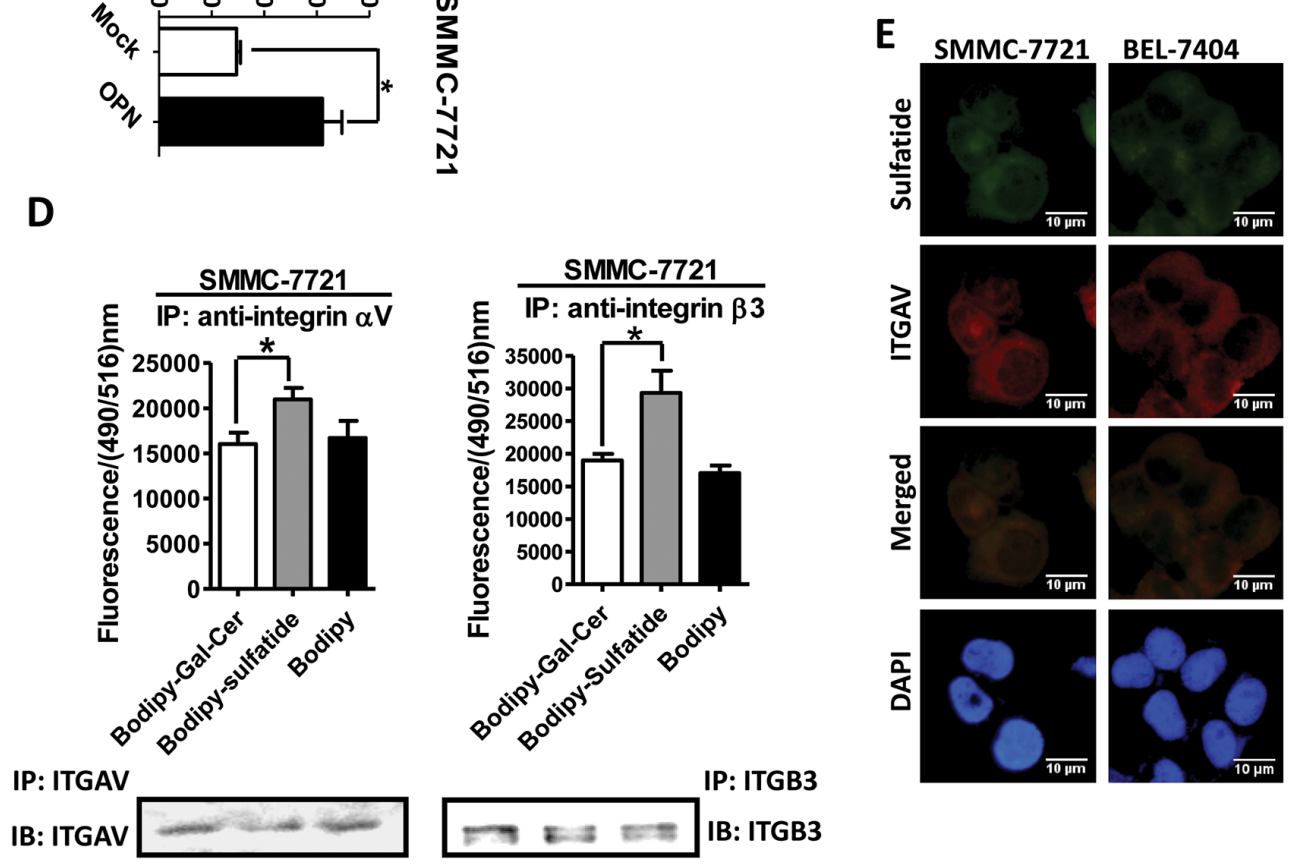

Figure 5: Interaction of sulfatide with integrin. A. Overexpression of OPN was validated by western blotting in the culture medium of SMMC-7721 cells after transfection (left). Integrin $\alpha \mathrm{V}, \beta 3$, FAK and Src were measured by western blotting in cells overexpressing OPN (right). CBB: Coomassie brilliant blue staining. B. Representative images of integrin $\alpha \mathrm{V} \beta 3$ clustering in OPN-overexpressing SMMC-7721 cells. Quantitative analysis is shown on lower panel. Green represents integrin $\alpha \mathrm{V} \beta 3$ and blue indicates nucleus. Original magnification: $400 \times$. C. Representative micrograph of wound healing assays in SMMC-7721 with OPN overexpression. The relative wound closure was quantitatively analyzed. D. Fluorescence signal was measured at a wavelength of $516 \mathrm{~nm}$ excited at $490 \mathrm{~nm}$ (Upper) after incubation with Bodipy-labeled sulfatide and immunoprecipitation by antibody against integrin $\alpha \mathrm{V}$ or $\beta 3$. The integrin proteins were determined via western blot analysis in the immunoprecipitated complex (Lower). E. Representative images of immunofluorescent staining of sulfatide and integrin $\alpha \mathrm{V}$ in SMMC-7721 and BEL-7404 cells. Co-localization, as indicated in Merged, is yellow. Original magnification: 400×. Data were representative of at least three independent experiments. $* P<0.05, * * P<0.01$. 

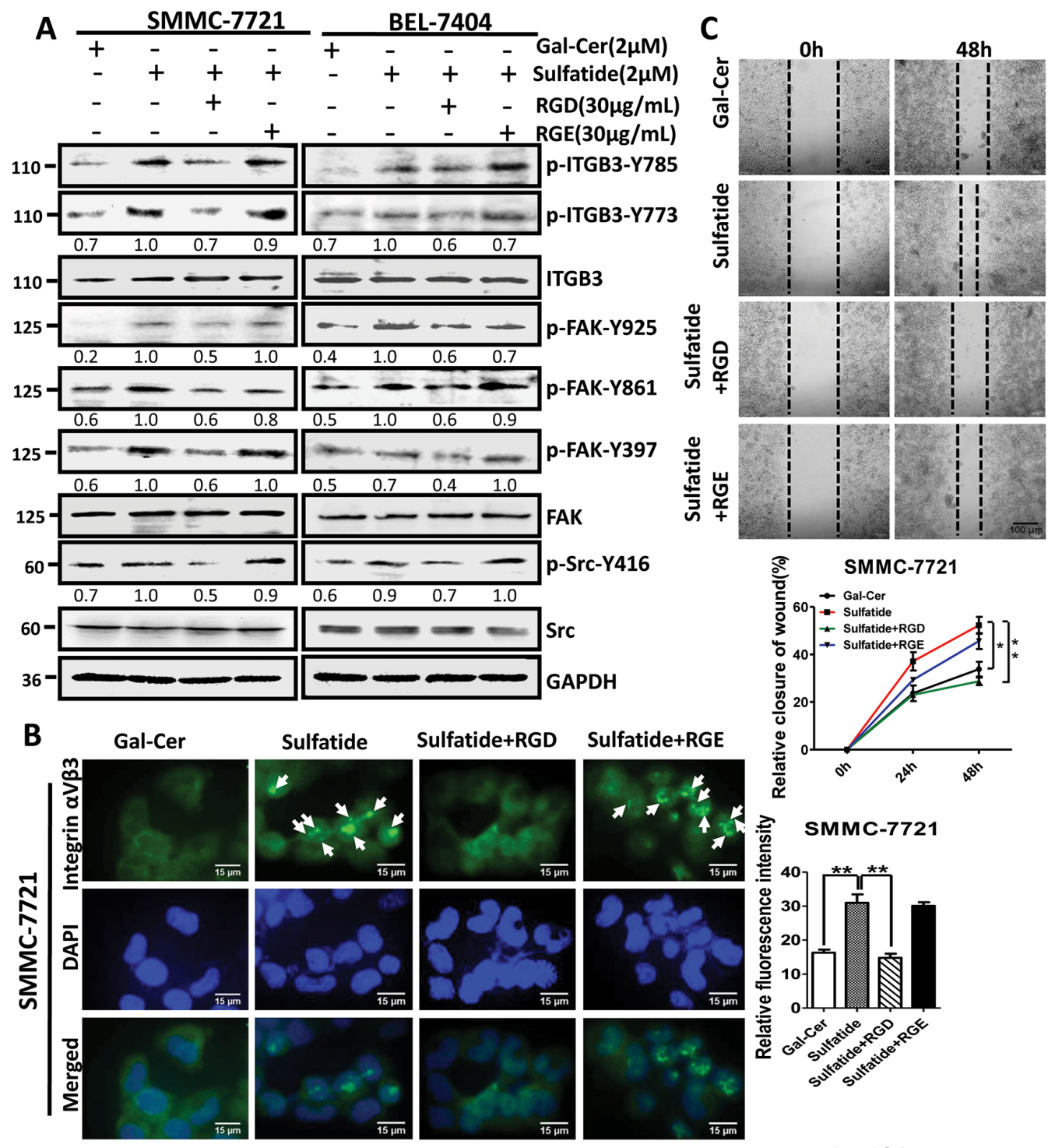

D
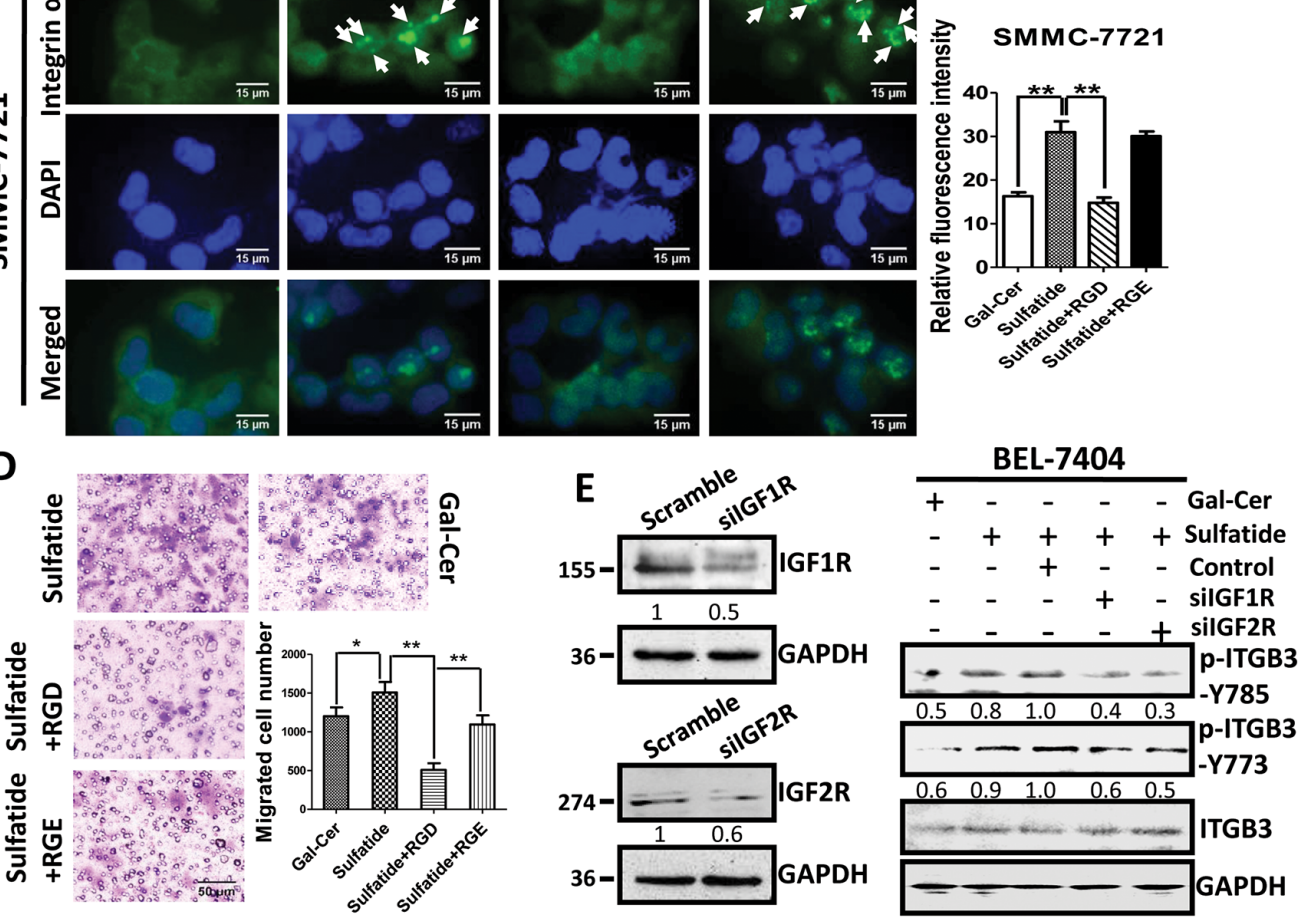

Figure 6: Interaction of sulfatide with integrin involved RGD. A. Phosphorylation of integrin $\beta 3$, Src and FAK was measured by western blotting in SMMC-7721 and BEL-7404 cells pretreated with RGD or RGE peptide $4 \mathrm{~h}$ prior to sulfatide. B. Representative images of the integrin $\alpha \mathrm{V} \beta 3$ clustering in SMMC-7721 cells pretreated with $30 \mu \mathrm{g} / \mathrm{mL}$ RGD or RGE 4 h prior to sulfatide. Green: integrin $\alpha \mathrm{V} \beta 3$; Blue: nucleus. Original magnification: $400 \times$. C. Representative images of wound closureand quantitative analysis. Original magnification: $100 \times$; bars: SD. D. Representative micrograph of migration in SMMC-7721 cells pretreated with $30 \mu \mathrm{g} / \mathrm{mL}$ RGD prior to sulfatide and quantitative analysis. E. Knockdown of IGFR expression (siIGF1, 2R) and the phosphorylation of integrin $\beta 3$ in SMMC-7721 cells. Knockdown of IGF1R or IGF2R was validated by western blotting (left panel). Levels of phosphorylated integrin $\beta 3-Y 773$ and $\beta 3$-Y785 were measured in the cells with IGF1R or IGF2R knockdown after sulfatide treatment (right panel). Data were representative of at least three independent experiments. Scramble: control plasmid, $* P<0.05, * * P<0.01$. 


\section{IGFR is important in phosphorylation of integrin $\beta 3$}

In sulfatide-induced activation of integrin $\beta 3 / F A K /$ Src signaling, integrin $\beta 3$ was phosphorylated. However, both integrin $\beta 3$ and sulfatide lack kinase activity. The phosphorylation of integrin $\beta 3$ subunit needs an additional kinase molecule. In this process of sulfatide-stimulated activation of integrin $\alpha \mathrm{V} \beta 3$, the inhibitors of Src kinase failed to prevent the phosphorylation of $\beta 3$ subunit. We silenced IGF1R and IGF2R to investigate their roles in the phosphorylation of integrin $\alpha \mathrm{V} \beta 3$ and the results indicated that the sulfatide-stimulated phosphorylation of integrin $\beta 3$ was suppressed in the cells with silenced IGF1R or IGF2R expression (siIGF1R and siIGF2R) (Figure 6E). Therefore, IGFRs were important in the phosphorylation of integrin $\beta 3$ subunit Tyr773 and Tyr785 induced by sulfatide.

\section{DISCUSSION}

Integrin $\alpha \mathrm{V}$ abnormality is associated with malignancy in many cancers. The tissues of non-small cell lung cancer were observed abnormal elevation of integrin $\alpha \mathrm{V}$ expression that was believed to promote tumor proliferation and progression [23]. Overexpression of integrin $\alpha \mathrm{V}$ correlates well with the shorter survival of patients with colorectal cancer [24]. Integrin $\alpha \mathrm{V} \beta 3$ mediates the interaction with extracellular matrix as an adhesion molecule, but overexpressed integrin $\alpha \mathrm{V} \beta 3$ initiates endothelial cell survival in anchorage independence and tumor metastasis without ECM ligand binding [5]. Integrin $\alpha \mathrm{V} \beta 3$ is also considered as the malignant driver of tumor cell stemness $[10,25]$. Thus, activation and clustering of integrin $\alpha \mathrm{V} \beta 3$ is important for tumor cell invasion, migration and metastasis. The present study showed that sulfatide significantly induced integrin $\alpha \mathrm{V} \beta 3$ clustering and stimulated phosphorylation of integrin $\beta 3$ intracellular tail on Tyr773 and Tyr 785. The phosphorylated intracellular domain of integrin $\beta 3$ subunit is important for mediating outside-in signaling since it triggers the signaling cascade [12]. We also observed that FAK-Y397 and Src-Y416 were phosphorylated and activated sequentially. FAK-Y397 was phosphorylated earlier than Src-Y416, since Src inhibitor did not suppress FAK-Y397 phosphorylation, and FAK inhibitor suppressed Src-Y416 phosphorylation even under sulfatide stimulation. Subsequent phosphorylation of FAK-Y861 and FAK-Y 925 was caused by Src activation since Src inhibitor also suppressed them. Paxillin, a scaffold protein, was phosphorylated after sulfatide treatment. This suggests that the signal sequence was similar to outsidein pattern. The phosphorylated tyrosine of paxillin was temporally and spatially regulated to provide additional binding sites for recruitment of signaling proteins to the plasma membrane, and to contribute to organization of the actin cytoskeleton at sites of focal adhesion [26].
Caveolin, which drives the formation of plasma membrane caveolae and anchors them to the actin cytoskeleton, was also phosphorylated. Phosphorylated caveolin-1 is implicated in mediation of focal adhesion turnover and integrin-regulated membrane domain internalization [27]. The rapid exchange of focal adhesion and internalization contributed to the cell migration of HCC stimulated by sulfatide, especially at the rear of the cells.

Tyrosine phosphorylation of integrin $\beta 1$ subunit inhibits talin and kindlin binding to NPXY sequence leaving room for other proteins to bind, for example, filamin and tensin [28]. Loss of talin and kindlin from the CT domain of integrin $\beta 3$ leads to inactivation of the integrin, which is conducive to recycling of integrin molecules and is important for persistent cell migration. The integrin $\beta 2$ subunit has tyrosine at 735 and mutation of this residue impairs integrin recycling [29] and cell migration. Integrin $\alpha \mathrm{V} \beta 3$ clustered upon sulfatide stimulation and $\beta 3$ subunit was phosphorylated. The phosphorylated integrin $\beta 3$ subunit provided a binding site for FAK-Y397 autophosphorylation. However, integrins have no kinase activity for themselves autophosphorylation, and phosphorylation of integrin $\beta 3$ subunit needs additional molecular involvement. The phosphorylation of threonine or serine on the cytoplasmic domain of $\beta$ subunit is related to protein kinase $\mathrm{C}$ and the small $\mathrm{G}$ protein signaling pathway. However, it is not clear and controversial for the tyrosine phosphorylation [30] located within NPXY and/or NPXY-like motifs, although association and interaction were noted between integrin $\beta 3 \mathrm{CT}$ and Src kinase [31]. Integrin $\beta 3$ phosphorylation by Src kinase should be reasonable in inside-out signaling of integrins. However, clustered integrin $\alpha \mathrm{V} \beta 3$ can mediate cross-activation of Src kinase that is in the complex to stimulate cell adhesion and migration upon ligand binding [17, 31], which fits outside-in signaling. In the current study, we observed that activation of Src was after FAK phosphorylation, which was similar to outside-in signaling of integrins, and interestingly noted the role of IGFR in the phosphorylation of integrin $\beta 3$ because sulfatide failed to stimulate integrin $\beta 3$ phosphorylation after silencing of IGF1R and IGF2R, suggesting integrin $\beta 3$ phosphorylation was associated with IGFR. This is consistent with our previous studies in which IGF1R was a functional target of miR-223 [32], and miR-223 expression is down-regulated by sulfatide in HCC [21]. Hence, sulfatide enhanced phosphorylation of integrin $\beta 3$ through regulation of IGF1R and miR-223. Additionally, IGFR can be physically linked to integrin $\alpha \mathrm{V} \beta 3$ in HCC [33], and formation of the complex $\alpha \mathrm{V} \beta 3$-IGF1R does not require IGF1R activation and $\beta 3$ phosphorylation [34]. Exogenous IGF stimulated $\beta 3$ (Y747) phosphorylation, although Src was blocked by Src inhibitor PP2, not depending on anchorage.

How sulfatide induces integrin $\alpha \mathrm{V} \beta 3$ phosphorylation by IGFR after stimulation should be the next question. 
We then investigated the interaction between sulfatide and integrin $\alpha \mathrm{V} \beta 3$, and observed that sulfatide bound to integrin $\alpha \mathrm{V} \beta 3$ via the RGD binding domain. Blocking this domain by RGD peptide suppressed sulfatide binding and integrin $\alpha \mathrm{V} \beta 3$ clustering or phosphorylation. Therefore, it was the sulfatide binding that induced clustering and phosphorylation of integrin $\alpha \mathrm{V} \beta 3$. Integrin clustering classically requires the interaction with and binding of ECM ligands to induce activation of integrin. As integrin binds to the ECM ligand, it forms the first contact with the ECM in the lamellipodia, and the integrin activator, talin or kindlin associates with the cytoplasmic domain of the $\beta$ subunit to induce conformational change and integrin activation. This process is followed by integrin lateral movement on the membrane, clustering, and phosphorylation of $\beta$ subunit. Sulfatide, as an important component of the cell membrane, is often elevated in HCC [18]. The elevated sulfatide stimulated integrin $\alpha \mathrm{V}$ expression. The increased integrin $\alpha \mathrm{V}$ formed $\alpha \mathrm{V} \beta 3$ with $\beta 3$ integrin and interacted with sulfatide, leading to $\alpha \mathrm{V} \beta 3$ clustering and $\beta 3$ cytoplasmic tail phosphorylation that provided a binding site for FAK autophosphorylation. Src was then activated and acted as an oncogenic driver to stimulate proliferation in anchorage-independence. Therefore interaction of sulfatide with integrin $\alpha \mathrm{V} \beta 3$ substituted ECM ligand binding to integrin $\alpha \mathrm{V} \beta 3$ and induced integrin $\alpha \mathrm{V} \beta 3$ clustering and phosphorylation which sent signals to FAK-Src pathway to accelerate cell growth in HCC independent on ECM ligand binding.

\section{MATERIALS AND METHODS}

\section{Materials}

Rabbit antibodies against phosphorylated FAK (pFAK, Tyr397, Tyr861 and Tyr925), phospho-paxillin-Y31, phospho-caveolin-1-Y14, phosphorylated integrin $\beta 3$ (Tyr773/Tyr785) and non-phosphorylated FAK, paxillin and caveolin-1 were from Bioworld Technology (St. Louis Park, MN, USA). Phosphorylated FAK Tyr407 was from Abcam (Cambridge, UK). Phospho-Src-Y416 was from Cell Signaling Technology (Danvers, MA, USA). Antibodies against integrin $\alpha \mathrm{V}, \beta 3$, Src and FAK inhibitor 14 were from Santa Cruz Biotechnology (Santa Cruz, CA, USA). Integrin $\alpha$ V $\beta 3$ antibody LM609 was from Millipore (Temecula, CA, USA). Integrin $\beta 1$ and $\beta 5$ antibodies, PP2(1HPyrazolo[3,4-d]pyrimidin-4-amine, 3-(4-chlorophenyl)1-(1,1-dimethylethyl)-) and SU6656((Z)-N,N-dimethyl2-oxo-3-((4,5,6,7-tetrahydro-1H-indol-2-yl)methylene) indoline-5-sulfonamide) were from Merck (Darmstadt, Germany). Sulfatide, galactocerebroside, lactocerebroside and ganglioside (GM3) were from Sigma-Aldrich (St. Louis, MO, USA). Peptides GRGDSP and GRGESP with 99\% purity were provided by China Peptides Co. (Shuzhou, China). Bodipy FL-C5 was from Molecular Probes (Carlsbad, CA, USA).

\section{Cell culture}

HCC cell lines SMMC-7721 and BEL-7404 were obtained from Shanghai Institute of Biochemistry and Cellular Biology, Chinese Academy of Science, and authenticated. Cells were cultured in Dulbecco's Modified Eagle's Medium (DMEM; Gibco, NY, USA) complete medium containing $10 \%$ newborn calf serum. For treatment, cells were cultured in DMEM containing $2 \mu \mathrm{M}$ sulfatide, galactocerebroside, or lactocerebroside from stock solution in DMSO. An equal amount of DMSO $(0.1 \% \mathrm{v} / \mathrm{v})$ was added to the control group.

\section{Plasmid construction}

The short hairpin sequences, 5'-GATCCGCTGAG CTCATCGTTTCCATTCAAGAGATGGAAACGATGA GCTCAGCAGA-3' and 5'-AGCTTCTGCTGAGCTCAT CGTTTCCATCTCTTGAATGGAAACGATGAGCTCAG CG-3', which specifically targeted the mRNAs of integrin $\alpha \mathrm{V}$ subunit, 5'-GATCCCCAAGACTCATATAGCATTT TCAAGAGAAATGCTATATGAGTCTTGGAGA-3' and 5'-AGCTTCTCCAAGACTCATATAGCATTTCTCTTGA AAATGCTATATGAGTCTTGGG-3' for targeting integrin $\beta 3$ subunit, 5'-GATCCGCGGCTGGAAACTCTTCTATT CAAGAGATAGAAGAGTTTCCAGCCGCAGA-3' and 5'-AGCTTCTGCGGCTGGAAACTCTTCTATCTCTTG AATAGAAGAGTTTCCAGCCGCG-3' for insulin-like growth factor 1 receptor (IGF1R), 5'-GATCCCCTGGG AACTCCTGAATTTTTCAAGAGAAAATTCAGGAGT TCCCAGGAGA-3' and 5'-AGCTTCTCCTGGGAACTC CTGAATTTTCTCTTGAAAAATTCAGGAGTTCCCAG GG-3' for IGF2 receptor (IGF2R) were designed through the website of Life Technologies (http://rnaidesigner. lifetechnologies.com/rnaiexpress/design.do). Synthetic 55-bp oligonucleotides containing the siRNA sequences were annealed and ligated to pSilencer 4.1 vector. Tyrosine to phenylalanine mutations of integrin $\beta 3$ at 773 and 785 were introduced into the integrin $\beta 3$ cDNA by PCR mutagenesis using primers consisting of 5'-AAAGAATTCATGCGAGCGCGGCC-3', 5'-TGGCT TCTTTAAACAGTGGGT-3', 5'-CAACAACCCACTGT TTAAAGAGG-3', and 5'-GGGTCTAGATTAAGTGCC CCGGAACGTGAT-3'.

\section{Western blotting}

After cells were harvested and lysed with 1\% SDS containing $50 \mathrm{mM} \mathrm{NaF}, 1.5 \mathrm{mM} \mathrm{Na}_{3} \mathrm{VO}_{4}$, and $0.5 \mathrm{mM}$ phenylmethanesulfonyl fluoride (PMSF). The protein was resolved on $10 \%$ SDS-polyacrylamide gels and electrophoretically transferred to a polyvinylidene fluoride membrane. Blocked with $8 \%$ milk for $2 \mathrm{~h}$ at room temperature, membranes were incubated overnight with primary antibodies. After washing, the blots were incubated with horseradish-peroxidase-conjugated secondary antibody, and protein bands were visualized 
using enhanced chemiluminescence detection kit and captured by an E/M camera. The density of protein bands was analyzed with Band Analyzer software(Tenon, Shanghai, China).

\section{Clustering and immunofluorescence}

The cells were incubated with $2 \mu \mathrm{M}$ Gal-Cer, sulfatide or $10 \mu \mathrm{g} / \mathrm{ml}$ anti-integrin $\alpha \mathrm{V} \beta 3$ antibody for $1 \mathrm{~h}$ at $10^{\circ} \mathrm{C}$ in DMEM. Cells were fixed with freshly prepared 4\% paraformaldehyde in PBS for $20 \mathrm{~min}$ at room temperature, and blocked with $1 \%$ bovine serum albumin in PBS for $2 \mathrm{~h}$ at room temperature without permeabilization. Cells were incubated with primary antibodies against integrin $\alpha \mathrm{V}$ or $\alpha \mathrm{V} \beta 3$ overnight at $4^{\circ} \mathrm{C}$, followed by FITC-conjugated secondary antibody and DAPI (4',6-diamidino-2-phenylindole) at room temperature in the dark for $2 \mathrm{~h}$. The coverslips were mounted on glass slides. Images were captured using an Olympus fluorescent microscope (Tokyo, Japan).

\section{F-actin staining}

Before fixing, cells in a Lab-Tek chamber (Nunc, Naperville,IL) were treated with $2 \mu \mathrm{M}$ Gal-Cer or sulfatide for $48 \mathrm{~h}$ at $37^{\circ} \mathrm{C}$. After washing with PBS four times and permeabilization with $0.1 \%$ Triton-X-100 in PBS in a shaker for $5 \mathrm{~min}$, the cells on slides were incubated with rhodamine-phalloidin $(1 \mu \mathrm{g} / \mathrm{mL})$ and DAPI for $20 \mathrm{~min}$ at room temperature. Then slides were rinsed in PBS and mounted for microscopy. Images were captured using an Olympus fluorescent microscope.

\section{Wound healing assay}

The cells were seeded at a density of $5.0 \times 10^{5}$ cells into each well of six-well plates. The cell monolayers were scratched with a sterile micropipette tip, washed with PBS to remove the detached cells, and incubated with 2 $\mu \mathrm{M}$ sulfatide and Gal-Cer. The scratches were monitored every $24 \mathrm{~h}$ until they closed. The rate of wound closure was determined by calculating the percentage of the area covered by migrating cells in the initial wound. All experiments were repeated three times independently.

\section{Cell migration assay}

Cell suspensions $(100 \mu \mathrm{L})$ with $2 \mu \mathrm{M}$ Gal-Cer or sulfatide were seeded in Millicell inserts (Millipore, Billerica, MA, USA) with polyethylene terephthalate microporous membrane ( $8 \mu \mathrm{m}$ pore size) at a density of $2 \times 10^{5} / \mathrm{mL}$ in serum-free DMEM in triplicate, and medium containing $10 \%$ fetal bovine serum was added to the lower chamber. Cells were allowed to migrate across polyporous membrane for $12 \mathrm{~h}$ at $37^{\circ} \mathrm{C}$. The migrated cells on the downside of the membrane were fixed with methanol, stained with $0.5 \%$ crystal violet, and counted.
The average number of migrated cells was counted from three independent experiments. Each set of experiments was performed in triplicate separately.

\section{Bodipy labeling and immunoprecipitation}

Bodipy labeling assay was performed as described previously [35]. Sulfatide $(0.2 \mathrm{mg})$ reacted with $0.2 \mathrm{mg}$ Bodipy FL-C5 at room temperature for $1 \mathrm{~h}$ with shaking. After the reaction, labeled sulfatide was separated by thinlayer chromatography and dissolved in DMSO. The purified Bodipy-sulfatide was incubated with SMMC-7721 cell lysate in buffer containing $0.5 \%$ Nonidet P- $40,120 \mathrm{mM}$ $\mathrm{NaCl}, 50 \mathrm{mM}$ Tris- $\mathrm{HCl} \mathrm{pH}$ 8.0, $1 \mathrm{mM} \mathrm{Na} \mathrm{VO}_{4}, 10 \mu \mathrm{g} / \mathrm{mL}$ aprotinin, $2 \mathrm{mM}$ PMSF and $10 \mathrm{mM} \mathrm{NaF}$ for $1 \mathrm{~h}$ at $37^{\circ} \mathrm{C}$. The lysates were immunoprecipitated with anti-integrin $\alpha \mathrm{V}$ or $\beta 3$ antibody along with protein $\mathrm{A} / \mathrm{G}$-agarose beads. Immunocomplex-captured beads were washed with lysis buffer. Bodipy fluorescence was determined (excitation, $490 \mathrm{~nm}$; emission, $516 \mathrm{~nm}$ ). Afterwards, immunocomplexes captured by beads were boiled in Laemmli sample buffer. The proteins were separated by $10 \%$ SDS-PAGE and western blotted using anti-integrin $\alpha \mathrm{V}$ or $\beta 3$ antibody.

\section{Statistical analysis}

Data are presented as means \pm SD. Statistical differences were measured using one-way ANOVA and Student's $t$ test. Statistical significance was set at $P<0.05$ or $P<0.01$.

\section{ACKNOWLEDGMENTS}

This work was supported by grants from National Key Basic Research Program of China (2012CB822104) and the Natural Science Foundation of China (31400689, J1210041 and 31570800).

\section{CONFLICTS OF INTEREST}

The authors declare no conflict of interest.

\section{REFERENCES}

1. Zhang $\mathrm{X}$, Nie D and Chakrabarty S. Growth factors in tumor microenvironment. Front Biosci. 2010; 15:151-165.

2. Stupack DG, Puente XS, Boutsaboualoy S, Storgard CM and Cheresh DA. Apoptosis of adherent cells by recruitment of caspase-8 to unligated integrins. J Cell Biol. 2001; 155:459-470.

3. Brooks PC, Clark RA and Cheresh DA. Requirement of vascular integrin alpha $\mathrm{v}$ beta 3 for angiogenesis. Science. 1994; 264:569-571.

4. Brooks PC, Montgomery AM, Rosenfeld M, Reisfeld RA, $\mathrm{Hu}$ T, Klier $\mathrm{G}$ and Cheresh DA. Integrin alpha v beta 3 
antagonists promote tumor regression by inducing apoptosis of angiogenic blood vessels. Cell. 1994; 79:1157-1164.

5. Desgrosellier JS, Barnes LA, Shields DJ, Huang M, Lau SK, Prevost N, Tarin D, Shattil SJ and Cheresh DA. An integrin alpha(v)beta(3)-c-Src oncogenic unit promotes anchorage-independence and tumor progression. Nat Med. 2009; 15:1163-1169.

6. Ravelli C, Mitola S, Corsini M and Presta M. Involvement of alphavbeta3 integrin in gremlin-induced angiogenesis. Angiogenesis. 2013; 16:235-243.

7. Liu H, Radisky DC, Yang D, Xu R, Radisky ES, Bissell MJ and Bishop JM. MYC suppresses cancer metastasis by direct transcriptional silencing of alphav and beta3 integrin subunits. Nat Cell Biol. 2012; 14:567-574.

8. Bai J, Zhang J, Wu J, Shen L, Zeng J, Ding J, Wu Y, Gong Z, Li A, Xu S, Zhou J and Li G. JWA regulates melanoma metastasis by integrin alphaVbeta3 signaling. Oncogene. 2010; 29:1227-1237.

9. van den Hoogen C, van der Horst G, Cheung H, Buijs JT, Pelger RC and van der Pluijm G. Integrin alphav expression is required for the acquisition of a metastatic stem/progenitor cell phenotype in human prostate cancer. Am J Pathol. 2011; 179:2559-2568.

10. Desgrosellier JS and Cheresh DA. Integrins in cancer: biological implications and therapeutic opportunities. Nat Rev Cancer. 2010; 10:9-22.

11. Gruber G, Hess J, Stiefel C, Aebersold DM, Zimmer Y, Greiner RH, Studer U, Altermatt HJ, Hlushchuk R and Djonov V. Correlation between the tumoral expression of beta3-integrin and outcome in cervical cancer patients who had undergone radiotherapy. Br J Cancer. 2005; 92:41-46.

12. Deshmukh L, Gorbatyuk V and Vinogradova O. Integrin \{beta\}3 phosphorylation dictates its complex with the Shc phosphotyrosine-binding (PTB) domain. J Biol Chem. 2010; 285:34875-34884.

13. Law DA, DeGuzman FR, Heiser P, Ministri-Madrid K, Killeen $\mathrm{N}$ and Phillips DR. Integrin cytoplasmic tyrosine motif is required for outside-in alphallbbeta3 signalling and platelet function. Nature. 1999; 401:808-811.

14. Schaffner-Reckinger E, Gouon V, Melchior C, Plancon S and Kieffer N. Distinct involvement of beta3 integrin cytoplasmic domain tyrosine residues 747 and 759 in integrin-mediated cytoskeletal assembly and phosphotyrosine signaling. J Biol Chem. 1998; 273:12623-12632.

15. Oberprieler NG, Roberts W, Riba R, Graham AM, HomerVanniasinkam S and Naseem KM. cGMP-independent inhibition of integrin alphallbbeta3-mediated platelet adhesion and outside-in signalling by nitric oxide. FEBS Lett. 2007; 581:1529-1534.

16. Datta A, Huber F and Boettiger D. Phosphorylation of beta3 integrin controls ligand binding strength. J Biol Chem. 2002; 277:3943-3949.

17. Bhattacharya S, Ray RM and Johnson LR. Integrin beta3mediated Src activation regulates apoptosis in IEC-6 cells via Akt and STAT3. Biochem J. 2006; 397:437-447.
18. Takahashi T and Suzuki T. Role of sulfatide in normal and pathological cells and tissues. J Lipid Res. 2012; 53:1437-1450.

19. Wu XZ, Honke K, Long Zhang Y, Liang Zha X and Taniguchi N. Lactosylsulfatide expression in hepatocellular carcinoma cells enhances cell adhesion to vitronectin and intrahepatic metastasis in nude mice. Int J Cancer. 2004; 110:504-510.

20. Wu W, Dong YW, Shi PC, Yu M, Fu D, Zhang CY, Cai QQ, Zhao QL, Peng M, Wu LH and Wu XZ. Regulation of integrin alphaV subunit expression by sulfatide in hepatocellular carcinoma cells. J Lipid Res. 2013; 54:936-952.

21. Dong YW, Wang R, Cai QQ, Qi B, Wu W, Zhang YH and $\mathrm{Wu}$ XZ. Sulfatide epigenetically regulates miR-223 and promotes the migration of human hepatocellular carcinoma cells. J Hepatol. 2014; 60:792-801.

22. Courter D, Cao H, Kwok S, Kong C, Banh A, Kuo P, Bouley DM, Vice C, Brustugun OT, Denko NC, Koong AC, Giaccia A and Le QT. The RGD domain of human osteopontin promotes tumor growth and metastasis through activation of survival pathways. PLoS One. 2010; 5:0009633.

23. Fu S, Fan L, Pan X, Sun Y and Zhao H. Integrin alphav promotes proliferation by activating ERK $1 / 2$ in the human lung cancer cell line A549. Mol Med Rep. 2015; 11:1266-1271.

24. Ha SY, Shin J, Kim JH, Kang MS, Yoo HY, Kim HH, $\mathrm{Um} \mathrm{SH}$ and Kim SH. Overexpression of integrin alphav correlates with poor prognosis in colorectal cancer. J Clin Pathol. 2014; 67:576-581.

25. Seguin L, Kato S, Franovic A, Camargo MF, Lesperance J, Elliott KC, Yebra M, Mielgo A, Lowy AM, Husain H, Cascone T, Diao L, Wang J, Wistuba, II, Heymach JV, Lippman SM, et al. An integrin beta(3)-KRAS-RalB complex drives tumour stemness and resistance to EGFR inhibition. Nat Cell Biol. 2014; 16:457-468.

26. Turner CE. Paxillin and focal adhesion signalling. Nat Cell Biol. 2000; 2:E231-236.

27. del Pozo MA, Balasubramanian N, Alderson NB, Kiosses WB, Grande-Garcia A, Anderson RG and Schwartz MA. Phospho-caveolin-1 mediates integrin-regulated membrane domain internalization. Nat Cell Biol. 2005; 7:901-908.

28. Gahmberg CG, Gronholm M and Uotila LM. Regulation of integrin activity by phosphorylation. Adv Exp Med Biol. 2014; 819:85-96.

29. Fabbri M, Fumagalli L, Bossi G, Bianchi E, Bender JR and Pardi R. A tyrosine-based sorting signal in the beta2 integrin cytoplasmic domain mediates its recycling to the plasma membrane and is required for ligand-supported migration. EMBO J. 1999; 18:4915-4925.

30. Gahmberg CG, Fagerholm SC, Nurmi SM, Chavakis T, Marchesan S and Gronholm M. Regulation of integrin activity and signalling. Biochim Biophys Acta. 2009; 1790:431-444. 
31. Huveneers S and Danen EH. The interaction of SRC kinase with beta3 integrin tails: a potential therapeutic target in thrombosis and cancer. ScientificWorldJournal. 2010; 10:1100-1105.

32. Jia CY, Li HH, Zhu XC, Dong YW, Fu D, Zhao QL, Wu $\mathrm{W}$ and $\mathrm{Wu} \mathrm{XZ}$. MiR-223 suppresses cell proliferation by targeting IGF-1R. PLoS One. 2011; 6:2.

33. Nussbaum $T$, Samarin $J$, Ehemann $V$, Bissinger $M$, Ryschich E, Khamidjanov A, Yu X, Gretz N, Schirmacher $\mathrm{P}$ and Breuhahn K. Autocrine insulin-like growth factor-II stimulation of tumor cell migration is a progression step in human hepatocarcinogenesis. Hepatology. 2008; 48:146-156.
34. Fujita M, Takada YK and Takada Y. Insulin-like growth factor (IGF) signaling requires alphavbeta3-IGF1-IGF type 1 receptor (IGF1R) ternary complex formation in anchorage independence, and the complex formation does not require IGF1R and Src activation. J Biol Chem. 2013; 288:3059-3069.

35. Li S, Liquari P, McKee KK, Harrison D, Patel R, Lee S and Yurchenco PD. Laminin-sulfatide binding initiates basement membrane assembly and enables receptor signaling in Schwann cells and fibroblasts. J Cell Biol. 2005; 169:179-189. 